\title{
O USO DO GEOPROCESSAMENTO NO DIAGNÓSTICO DOS Roteiros de coleta de liXo da cidade de MANAUS
}

\section{THE USE OF GEOPROCESSING IN THE DIAGNOSIS OF THE ROUTES OF GARBAGE COLLECTION IN THE CITY OF MANAUS}

\begin{abstract}
José OLAVO NOGUEIRA BRAGA
Engenheiro Ambiental (ULBRA/Manaus). Mestre em Ciências Florestais e Ambientais (UFAM). Assessor Técnico da Secretaria Municipal de Limpeza Pública de Manaus

\section{LIZIT ALENCAR DA COSTA}

Professor e Pesquisador do Departamento de Ciências Florestais da UFAM. Doutor pela Universidade Federal de Viçosa/MG

\section{ANDRÉ LUIZ GUIMARÁES}

Doutor em Engenharia Ambiental pela Universidade de Hiroshima. Consultor da Central de Tratamento de Resíduos da Amazônia Ltda. - CETRAM

\section{Julio César Rodrigues TelLo}

Professor e Pesquisador do Departamento de Ciências Florestais da UFAM.Doutor em Botânica pelo INPA/UFAM

$$
\text { Recebido: 07/05/07 Aceito: 16/07/08 }
$$

\section{RESUMO}

A partir da necessidade de garantir a melhoria continua da Limpeza Pública de Manaus e possibilitar a ampliação da prestação do serviço de coleta de lixo, que atualmente é gerenciado pela Secretaria Municipal de Limpeza Urbana - SEMULSP, e realizado pelas empresas concessionárias de coleta de lixo, utilizou-se o geoprocessamento, com o intuito de analisar o atual sistema. Para analisar o sistema, fez-se um diagnóstico dos roteiros de coleta, onde se mapeou todas as informaçôes identificadas em campo, declividade, ruas sem asfalto e estreitas, lixeiras viciadas, tempo e distâncias dos trechos produtivos e improdutivos, produção de lixo e disposição do trânsito, com o auxílio de receptores GPS.

\begin{abstract}
In order to promote the continuous improvement of Public Cleansing System in Manaus as well as the expansion of garbage collection, currently operated by private contractors, the Municipal Secretary of Urban Cleansing - SEMULSP has performed an integrated analyses of the existing collection service design in geoprocessing, so as to identify possible improvements in the system. Aiming the practical evaluation of the present system, an assessment of the collection routes was performed, by collecting, georeferencing and mapping all related features, as slopes, road conditions, dead-endstreets, narrow lanes, illegal dumping, time taken and trip distance of productive and unproductive routes, waste quantity and traffic conditions. Most of data were taken by GPS equipments.
\end{abstract}

KEYWORDS: Public cleanness, GPS, diagnosis.

PALAVRAS-CHAVE: Limpeza pública, GPS, diagnóstico.

\section{INTRODUÇÃO}

Os serviços de coleta e transporte de lixo são realizados, dentre outros, mediante o estabelecimento de roteiros de coleta. Na prática estes devem corresponder a uma área possível de ser atendida por um veiculo coletor durante uma jornada de trabalho, podendo este, num turno, efetuar mais de uma viagem de descarga até o local de destinação final do lixo. Os roteiros costumam, portanto, contemplar aspectos da divisão administrativa de uma cidade (bairros, conjuntos, condomínios, comunidades e distritos).
A quantidade de lixo gerado nos domicílios varia conforme o dia da semana e do mês, condições climáticas, datas comemorativas e outros eventos extemporâneos, como, o desempenho da economia, o poder de compra da população entre outros, consequentemente, fazendo com que a quantidade de lixo coletado em um roteiro varie ao longo da semana, do mês e do ano.

O peso do lixo pode variar em função de mudanças tecnológicas nas embalagens de produtos de consumo, como por exemplo, no caso de diminuição de peso de uma nova embalagem de um mesmo produto.
A densidade populacional das áreas urbanas varia ao longo do tempo, podendo haver adensamento, verticalização, ou até mesmo, em alguns casos, diminuição da população residente através do aumento do número de estabelecimentos empresariais.

Segundo Stroski (2002) a população de Manaus cresce em ritmo acelerado e apresenta uma dispersão populacional que por sua vez exige maior utilização dos recursos naturais.

A quantidade de lixo coletado em um roteiro também pode variar ao longo do tempo em função de fatores socioeconômicos e culturais que possam 
redundar em uma alteração do padrão de consumo de uma determinada população.

A coleta de lixo domiciliar em Manaus tem seu custo calculado em função do peso coletado e de um preço específico para cada tipo de serviço. O trabalho é executado diariamente ao longo da semana, com exceção do domingo (dia em que não há coleta), em dois turnos de trabalho (diurno e noturno). Nas regiões centrais, em função do tráfego intenso no período diurno, a coleta é executada no turno da noite.

O tipo de equipamento empregado no atendimento de um roteiro de coleta depende, dentre outros aspectos, das características das vias urbanas e da distância do ponto de descarga. O uso de equipamentos de maior capacidade volumétrica pode resultar em um menor número de viagens de carga-descarga. Entretanto, tal uso requer atenção, a fim de evitar dificuldades de manobras em vias estreitas. Por sua vez, o uso de equipamentos coletores compactadores com uma maior taxa de compactação, pode também, resultar em um menor número de viagens de carga-descarga, sem aumentar o volume do equipamento, estando, entretanto, limitado à capacidade de suporte do pavimento.

Em função de todas as variáveis aqui expostas, a exata definição da área de abrangência de um roteiro de coleta de lixo domiciliar é um procedimento bastante complexo e determinante para a máxima eficiência operacional.

A possibilidade que se tem a partir da utilização do SIG - Sistema de Informaçôes Geográficas, em análises que contemplem aspectos de distribuição espacial da geração do lixo e informaçôes sobre situação socioeconômica, densidade populacional e outras, abre a perspectiva para a utilização desta ferramenta na definição e administração dos roteiros de coleta de lixo.

A partir da necessidade da Secretaria Municipal de Limpeza Urbana de ampliar e promover a melhoria continua da prestação do serviço de coleta de lixo, utilizou-se o geoprocessamento, para analisar o sistema atual e possibilitar que a partir de informaçôes confiáveis e precisas, seja possível, planejar e redimensionar os roteiros de coleta, com o intuito de melhorar a eficiência operacional do sistema.

\section{REVISÃO DE LITERATURA}

\section{Sistema de limpeza urbana}

No sistema de limpeza urbana de uma cidade a coleta de lixo domiciliar pode apresentar roteiros, considerados críticos, do ponto de vista de eficiência operacional, ou seja, roteiros que necessitem de redimensionamento por contemplarem percursos improdutivos com grandes extensões percorridas e pouco volume de lixo coletado. As condiçôes de acesso ao ponto de coleta também são aspectos que interferem na eficiência operacional. Ruas não pavimentadas, estreitas ou inexistentes, como ocorrem em favelas, dificultam e até impedem o acesso de caminhōes coletores para a coleta porta-a-porta (IPT, 2000).

Em Manaus, boa parte dos roteiros considerados críticos encontra-se nas localidades compreendidas em áreas periféricas das zonas Leste, Oeste e Norte de Manaus. Isto se verifica, em função do crescimento desordenado e da falta de planejamento urbano destas áreas.

Segundo Bretas (2002), a coleta e transporte de lixo regular, dentre as demais atividades de limpeza pública, é a que gera, pela população, reclamações intensas e imediatas quando da sua não realização.

$\mathrm{O}$ aumento ou diminuição da população, as mudanças de características de bairros e a existência do recolhimento irregular do lixo são alguns fatores que indicam a necessidade de redimensionamento dos roteiros de coleta (IBAM, 2001).

Conforme o Instituto Brasileiro de Administração Municipal - IBAM (2001), o método de dimensionamento de roteiros de coleta de lixo domiciliar, basicamente consiste em dividir a cidade em roteiros (subáreas), dimensionar, determinar e sistematizar as características de cada roteiro, analisar as informaçôes levantadas e redimensionar os roteiros, tendo como premissas: a exclusão ou minimização de horas extras de trabalho; o estabelecimento de novos pesos de coleta por jornada; as concentrações de lixo em cada área.

A Associação Nacional de Serviços Municipais de Saneamento - ASSEMAE (1995) caracteriza como setores de coleta sub-dimensionados os roteiros que apresentam um bom atendimento, mas um alto custo de coleta, decorrente do desperdício na utilização dos recursos disponíveis, e caracteriza como setores sobre-dimensionados, os roteiros que a sobrecarga, implica diretamente na equipe de coleta e no veículo coletor, com prejuízos ao atendimento, ao custo e até mesmo ao asseio, em função da necessidade freqüente de mobilizar reforços para atendimento ao setor, e da sobrecarga do pessoal e do equipamento.

Considera-se que o melhor indicador do nível de produtividade com que a coleta é efetuada é o MHC - Massa por Hora de Coleta, parâmetro que é bastante variável para as diferentes regiōes de uma mesma cidade, e considera-se como principal condicionador da produtividade horária da coleta, o nível de concentração dos resíduos no distrito, o qual é medido pela taxa MKC - Massa por Quilômetro de Coleta (ASSEMAE, 1995).

Conforme o IPT (2000), para o dimensionamento de roteiros de coleta, deve ser estimado os seguintes parâmetros operacionais: distância entre a garagem da empresa e o roteiro de coleta; distância entre o roteiro de coleta e o ponto de descarga; extensão total das vias do roteiro; velocidade média de coleta que dependerá do sistema viário, da topografia, do tamanho da guarnição, da quantidade de lixo a ser coletada por unidade de distância e do carregamento do veículo; velocidade média dos veículos nos percursos entre a garagem e o roteiro de coleta e entre o roteiro e o ponto de descarga e vice-versa.

Os itinerários de coleta devem ser projetados de maneira a minimizar os percursos improdutivos (nos quais não há coleta). Estes roteiros devem ser planejados de tal forma que as guarniçôes comecem seu trabalho no ponto mais distante do local de destino do lixo e, com a progressão do trabalho, se movam na direção daquele local reduzindo as distâncias e o tempo de percurso (IBAM, 2001).

Segundo o Centro Pan-americano de Engenharia Sanitária e Ambiental - CEPIS (2002), as rotas de coleta de lixo domiciliar devem ter as seguintes características: evitar duplicaçôes, repetiçôes e movimentos desnecessários; contemplar as disposições do trânsito, minimizar o número de retornos para evitar perda de tempo, reduzir o perigo de acidentes e minimizar os obstáculos 
de tráfego; as rotas com muito tráfego devem ser realizadas no turno noturno; as rotas devem iniciar nos pontos mais distantes do roteiro e à medida que o trabalho avança, este deve seguir em direção ao lugar de transferência ou de destinação final.

Quanto ao tempo total da jornada de trabalho, segundo a CLT - Consolidação das Leis Trabalhistas, o mesmo deve ser de 44 horas semanais (Brasil, 1943).

Em 2006, devido a uma constante carga de horas extras semanais na coleta de lixo domiciliar de Manaus, o Tribunal Regional do Trabalho determinou a realização de um estudo de ergonomia.

Cavalcante (2007), concluiu através de uma análise ergonômica do trabalho para o postos de coletores de lixo e motoristas, que o tempo máximo adequado para a jornada de trabalho deve ser de 440 minutos, com mais 60 minutos de descanso, ou seja, uma jornada diária de 500 minutos para cada roteiro de coleta de lixo.

\section{O geoprocessamento na limpeza urbana}

Conforme Rodrigues (1993), geoprocessamento é um conjunto de tecnologias, de coleta, tratamento, manipulação e apresentação de informaçóes espaciais voltado para um objetivo específico.

Segundo Câmara e Medeiros (1998), o termo geoprocessamento denota uma disciplina do conhecimento que utiliza técnicas matemáticas e computacionais para o tratamento de informaçōes geográficas.

Christofoletti (1999), afirma que geoprocessamento é o processamento digital de informações espaciais georreferenciadas.

Para Silva \& Zaidan (2004) a principal característica do geoprocessamento é permitir a investigação sistemática das propriedades e relaçóes posicionais dos eventos e entidades representados em uma base de dados georreferenciados, transformando dados em informaçáo destinada ao apoio à tomada de decisão.

Rocha (2000) define geoprocessamento como uma tecnologia transdisciplinar, que através da localização e do processamento de dados geográficos, integra várias disciplinas, equipamentos, programas, processos, entidades, dados, metodologias e pessoas para coleta, tratamento, análise e apresentação de informações associadas a mapas digitais georreferenciados, e utiliza como principal ferramenta o Sistema de Informação Geográficas (SIG).

A literatura especializada apresenta um grande número de artigos sistematizando o conceito de um "SIG", assim como Cruz (1996), Assad \& Sano (1998) e Davis Junior (2000), que definem o termo Sistema de Informação Geográfica como a caracterização dos sistemas de informação, que tornam possível a captura, modelagem, manipulação, recuperação, armazenamento, tratamento, integração, processamento, análise e apresentação de informações digitais georreferenciadas, topologicamente estruturadas, associadas ou não a um banco de dados.

Segundo Calijuri \& Rohm (1995), a tecnologia utilizada nos (SIGs), pode ser direcionada para a investigação de diversos fenômenos relacionados com o meio ambiente, geologia, pedologia, vegetação, bacias hidrográficas, e em especifico à engenharia urbana, podendo ser observado na avaliação e no gerenciamento de: serviços de transportes, equipamentos urbanos, uso e ocupação do solo, cadastramento de imóveis, ruas, escolas, hospitais, postos de saúde, áreas de lazer, áreas de proteção ambiental, redes de infra-estrutura urbana (água, esgoto, pavimentação, iluminação, limpeza pública, telefonia, etc.) e também, fornecer subsídios para tomada de decisões referentes ao redimensionamento destas utilidades, quando se conclui que a população não está sendo adequadamente atendida por qualquer um dos itens anteriores.

Conforme Câmara (1995), um SIG, se caracteriza por integrar numa única base de dados, informaçóes provenientes de dados cartográficos, dados de censo, cadastro urbano e rural, imagens de satélite, redes e modelos numéricos de terreno. Sendo também capazes de oferecer mecanismos para combinar informações através de algoritmos de manipulação e análise, para consultar, recuperar, visualizar e plotar o conteúdo da base de dados geocodificados.

De acordo com Dantas (1996), o SIG tem-se destacado por integrar diferentes tipos de dados, considerar barreiras geográficas, eliminar decisóes subjetivas e realizar diversas simulaçôes.

Para Christofoletti \& Teixeira (1997), um SIG pode ser visto como a combinação de hardware, software, dados, metodologias e recursos humanos, que operam de forma harmônica para produzir e analisar informações geográficas.

Camargo (1997) destaca como as principais potencialidades do SIG, a capacidade de manipulação de um volume de dados informatizado de armazenamento e recuperação de dados sobre sistemas convencionais, seja através da capacidade de manipulação de um volume de dados muito maior e com eficiência, capacidade de cruzamento de dados, rapidez e flexibilidade na recuperação de dados, maior variedade de formas de apresentação e um maior e melhor acesso a métodos de modelagem estatística e gráfica para análise e interpretação de dados.

Conforme Halliday (2003), o uso de tecnologia de ponta para formular hipóteses e avaliar cenários alternativos é primordial para a otimização de serviços de coleta e transporte de resíduos urbanos.

No Brasil, as empresas de limpeza pública aos poucos começam a adotar na coleta domiciliar, rastreadores GPS acoplados aos caminhões coletores como forma de monitoramento operacional, como por exemplo, as cidades de Fortaleza e Salvador.

$\mathrm{Na}$ maioria das vezes a tecnologia utilizada por estes sistemas de rastreamento, está associada a softwares, com poucas funcionalidades, ou ainda, não adaptados especificamente às características de limpeza pública, possibilitando somente, a visualização espacial dos veículos em mapas cadastrais urbanos e à leitura em banco de dados de informaçôes de posicionamento, distância, velocidade e horário, não possibilitando análises espaciais mais aprofundadas como nos SIG's.

Outra aplicação que envolve conceitos de geoprocessamento e que também vem se difundido entre os gestores da limpeza pública é a aplicação de softwares SIG, em sistemas roteadores e de programação de veículos, que são utilizados na definição dos itinerários mais adequados para cada área de abrangência de um roteiro de coleta de lixo domiciliar.

Segundo Farkuh Neto e Lima (2005), roteirização é a forma que vem sendo utilizada para designar o processo de determinação automatizada de um ou mais roteiros ou sequências de paradas a serem cumpridas por um veículo, 
objetivando visitar um conjunto de pontos geograficamente dispersos, em locais determinados, que necessitem de atendimento.

Melo e Ferreira Filho (2002) estudaram os principais sistemas roteadores e de programação de veículos disponíveis no mercado e constataram que a aplicação destes pode permitir ganhos significativos, tanto financeiros quanto operacionais. No entanto, a aquisição e a implementação deste tipo de sistema geram significativos custos, caracterizando-se como ponto negativo à sua aplicação, podendo sistemas mal implantados e/ou gerenciados trazerem problemas e prejuízos.

Ferreira (2006) afirma que os SIG's constituem ferramentas extremamente úteis no planejamento de rotas de veículos, pois combinam a utilização de dados espaciais apropriados de otimização e simulaçãa.

Entretanto, os sistemas roteadores, ainda estão restritos à otimização de itinerários em áreas previamente determinadas e não possibilitam a tomada de decisão na definição de áreas de abrangência, ou seja, definição de roteiros de coleta, áreas capazes de serem atendidas por um caminhão coletor em um turno de trabalho.

Em 2000, Gazolla e Silva, utilizaram um software do tipo "CAD”, para analisar os roteiros de coleta de lixo existentes na cidade de Pirapora, Minas Gerais e também na definição de novos roteiros de coleta de lixo "equilibrados do ponto de vista operacional".

Porém, a utilização de um software CAD, programa específico para desenho técnico, não permite análises e modelagens espaciais como em um SIG, pois o mesmo não oferece a possibilidade de associar atributos, objetos e feiçóes espaciais a um banco de dados.

A utilização do geoprocessamento na SEMULSP - Secretaria Municipal de Limpeza e Serviços Públicos iniciou-se em 2005, com o intuito de monitorar e planejar com informações mais precisas, os serviços prestados pela Secretaria como a extensão de ruas varridas, extensão de meio-fios pintados, extensão de ruas capinadas, extensão de jardinagem em canteiros, extensão de roteiros de coleta domiciliar, extensão de coleta seletiva etc.

Um exemplo disto é que ao analisar as informações disponíveis no Relatório de Gestão da SEMULSP, referente ao ano de 2004, constatou-se que exis- tiam informações superestimadas. Pois, conforme o referido relatório, em 2004, a extensão total de ruas varridas era de aproximadamente $800 \mathrm{~km}$, e através das ferramentas SIG, identificou-se que os roteiros de varrição tinham extensão linear total menor que $200 \mathrm{~km}$.

Pelo exemplo ficou evidente a importância da utilização do geoprocessamento, pois, possibilita a geração de informaçôes confiáveis, que subsidiem à tomada de decisão, seja por identificação dos dados de campo, planejamento, dimensionamento ou pelo monitoramento dos serviços prestados.

\section{MATERIAIS E MÉTODOS}

Para analisar o sistema de coleta de lixo domiciliar da área urbana de Manaus, fez-se um diagnóstico dos 85 roteiros, ou seja, todos os roteiros existentes, onde se mapeou as informações pertinentes ao desempenho operacional dos mesmos, com o auxílio de receptores GPS.

Os parâmetros adotados neste diagnóstico foram: número de viagens, produção de lixo, extensão percorrida (deslocamento total do veículo coletor de lixo) versus extensão de ruas, trechos de coleta e sem coleta, horário e localização do veículo coletor, ponto de lixo (acúmulo de lixo devidamente acondicionado geralmente localizado na entrada de becos), lixeira viciada (depósito irregular de lixo, geralmente em lotes vagos), trecho de rua com declividade acentuada (ruas íngremes em que o caminhão coletor apresenta dificuldades para subir e/ou descer), trechos de ruas sem asfalto, ruas estreitas, ruas sem saída e o tempo de qualquer tipo de parada do coletor.

Posteriormente ao trabalho de campo, foram utilizados os softwares Arc View 3.2 e Arc Gis 9.2 e a planta cadastral de Manaus, para processar, extrair e avaliar as informaçóes operacionais de cada roteiro de coleta de lixo.

\begin{tabular}{cc} 
Tabela I & $\begin{array}{c}\text { Representação do percentual médio do tempo produtivo, nos dias } \\
\text { cheios e vazios dos roteiros de coleta de lixo }\end{array}$ \\
\hline Característica do trecho & Tempo $(\%)$ \\
\hline $1^{\circ}$ trecho de coleta & 49,78 \\
$2^{\circ}$ trecho de coleta & 33,48 \\
$3^{\circ}$ trecho de coleta & 16,74 \\
Total & 100
\end{tabular}

\section{RESULTADOS}

\section{Tempo e peso coletado}

A avaliação da média dos tempos produtivos (tempo referente ao trecho em que o veículo coletor está coletando), considerando dias cheios (tendo a quantidade de lixo é maior nas segundas e terças-feiras) e vazios (quintas e sextas-feiras) é de 460 minutos. Este tempo médio refere-se à avaliação em roteiros com diferentes trechos de coleta, ou seja, quantidade de viagens de coleta e descargas (disposição final do lixo) necessárias para atendimento de um mesmo roteiro. É importante salientar que foi constatado que o número de trechos de coleta por roteiro não foi o mesmo, em função dos mesmos estarem desequilibrados quanto aos parâmetros de tempo e peso.

$\mathrm{Na}$ Tabela 1 encontram-se os registros do percentual médio do tempo produtivo nos dias cheios e vazios dos roteiros de coleta de lixo de Manaus.

$\mathrm{Na}$ Tabela 1 pode-se observar que dos trechos de coleta, o $3^{\circ}$ Trecho é o que apresenta menor percentual de tempo. Isso se verifica em função do desequilíbrio entre os roteiros de coleta, que devem ser redimensionados para uma quantidade igual de viagens para os roteiros.

Considerando a CLT - Consolidação das Leis Trabalhista, Decreto-Lei $\mathrm{n}^{\circ} 5452$, de 1 de Maio de 1943, e ainda, o estudo de ergonomia realizado em 2007 nos roteiros de coleta de lixo de Manaus, pela Empresa CRL Métodos e Técnicas de Segurança, Saúde e Meio Ambiente, conforme determinação do Tribunal Regional do Trabalho, o tempo máximo de trabalho por jornada deve ser de 440 minutos, com mais 60 minutos de descanso, ou seja, o tempo total da jornada diária de cada roteiro deve ser de 500 minutos.

Considerando ainda que o tempo de 60 minutos de descanso dos coletores em vista que não existe coleta domingo 
(garis) deve ser realizado durante os deslocamentos improdutivos de idas e vindas do aterro e que a média do tempo para roteiros com duas viagens é de 120 minutos, os roteiros devem ser dimensionados para atender o limite de tempo de 380 minutos para os trechos produtivos (trechos de coleta), podendo este ser dimensionado para 440 minutos, em roteiros com tempo improdutivo menor que a média.

Então, analisando a média dos tempos improdutivos e produtivos dos dias cheios e vazios, o tempo médio dos roteiros de coleta de lixo de Manaus é de 580 minutos (9 horas e 40 minutos), ou seja, 80 minutos a mais do que o permitido.

$\mathrm{Na}$ Tabela 2 encontram-se os tempos médios diários dos trechos de coleta dos roteiros analisados durante o diagnóstico, onde, considerou-se como tempo almejado, o intervalo de 380 a 440 minutos de coleta por dia.

Conforme o apresentado na Tabela 2, atualmente na coleta de lixo domiciliar de Manaus, 57 roteiros, ou seja, $67,22 \%$ apresentam tempo médio de coleta superior a 440 minutos por dia, outros 9 roteiros $(10,51 \%)$ apresentam tempo médio de coleta ocioso, ou seja, tempo de coleta menor que 380 minutos por dia e somente 19 roteiros, ou seja, 22,26\% atendem os limites de tempo de coleta estabelecidos entre 380 e 440 minutos/dia.

A média de peso coletado por roteiro em Manaus atualmente é de $16.968 \mathrm{~kg} / \mathrm{dia}$, enquadrando-se no limite de produtividade almejado entre 15.000 a $18.000 \mathrm{~kg} / \mathrm{dia}$. Mas, o peso médio total não revela o desequilíbrio existente nos roteiros. Na Tabela 3 é mostrada a variação das diferentes concentrações de peso diário de lixo nos roteiros de coleta.

De acordo com as informaçôes apresentadas na Tabela 3, assim, como na variável tempo, fica expressa a existência de desequilíbrio de massa coletada entre os roteiros. Dos 85 roteiros de coleta de lixo analisados, somente $36,47 \%$ apresentam desempenho no patamar estabelecido de 15 a 18 toneladas por dia. Sendo que 31,76\% dos roteiros apresentam uma média de pesagem diária, maior que o limite de 18 toneladas, ou seja, 27 roteiros apresentam carga coletada maior que a capacidade de suporte do equipamento, o que pode promover redução da vida útil do mesmo, ou ainda, ocasionar sua quebra durante a operação. Já o restante dos roteiros $31,76 \%$, ou seja, 27 roteiros apresentam carga inferior a 15 toneladas/dia, o que caracteriza baixa produtividade, sendo que $5,88 \%$ destes $31,76 \%$ possuem produção inferior a 10 toneladas por dia.

$\mathrm{Na}$ Tabela 4 apresenta-se o cruzamento dos parâmetros peso médio e tempo médio de coleta diária dos trechos de coleta dos roteiros analisados durante o diagnóstico. Considerou-se como Padrão, o intervalo de tempo de 380 a 440 minutos de coleta e o intervalo de peso entre 15 e 18 toneladas dia, Padrão Abaixo, o intervalo de tempo menor que 380 minutos de coleta e o intervalo de peso menor que 15 toneladas e Padrão Acima, o intervalo de tempo superior a 440 minutos e o intervalo de peso superior a 18 toneladas por dia.

De acordo com o cruzamento dos parâmetros peso coletado e tempo de coleta apresentado na Tabela 4, somente 8 roteiros de coleta, ou seja, 9,4\% atende os padróes de produtividades almejados.
Conforme os parâmetros operacionais, tempo de trabalho e peso de lixo coletado, observa-se a necessidade imediata de redimensionamento dos roteiros de coleta de lixo, seja pelo não cumprimento de jornadas de trabalho, baixa produtividade, excesso de carga e principalmente em função da necessidade continua da melhoria da prestação dos serviços de limpeza pública.

\section{Itinerários dos roteiros}

Em Manaus, são muitas as ruas que possuem a prestação de serviço de coleta de lixo, mas que o caminhão coletor não trafega. Isto ocorre em função de diversos aspectos que dificultam o acesso e/ou condições de tráfego, seja pela condição do pavimento, pela largura (vielas), por se tratar de uma rua sem saída (becos) ou ainda por possuir fiação de energia com baixa altura.

Para coletar o lixo nas áreas onde o caminhão coletor não possui acesso, o lixo é puxado, ou seja, coletado e transportado manualmente pelos garis até o caminhão coletor, ou ainda, depositado

Tabela 2 - Representação do tempo médio diário dos trechos produtivos dos roteiros de coleta de lixo

\begin{tabular}{ccc}
\hline Tempo de coleta & Qtd. de rotas & $\%$ \\
\hline Menor que 380 minutos & 9 & $10,51 \%$ \\
380 a 440 minutos & 19 & $22,26 \%$ \\
Maior que 440 minutos & 57 & $67,22 \%$ \\
Total geral & 85 & $100,00 \%$ \\
\hline
\end{tabular}

Tabela 3 - Representação do peso diário de lixo nos diferentes roteiros de coleta

\begin{tabular}{|c|c|c|c|c|c|}
\hline \multicolumn{2}{|c|}{ Peso coletado } & \multicolumn{2}{|c|}{ Qtd. de rotas } & \multicolumn{2}{|c|}{$\%$} \\
\hline \multicolumn{2}{|c|}{ Menor que $10.000 \mathrm{~kg}$} & \multicolumn{2}{|l|}{5} & \multicolumn{2}{|c|}{$5,88 \%$} \\
\hline \multicolumn{2}{|c|}{10.000 a $14.999 \mathrm{~kg}$} & \multicolumn{2}{|l|}{22} & \multicolumn{2}{|c|}{$25,88 \%$} \\
\hline \multicolumn{2}{|c|}{15.000 a $18.000 \mathrm{~kg}$} & \multicolumn{2}{|l|}{31} & \multicolumn{2}{|c|}{$36,47 \%$} \\
\hline \multicolumn{2}{|c|}{ Maior que $18.000 \mathrm{~kg}$} & \multicolumn{2}{|l|}{27} & \multicolumn{2}{|c|}{$31,76 \%$} \\
\hline \multicolumn{2}{|c|}{ Total geral } & \multicolumn{2}{|l|}{85} & \multicolumn{2}{|c|}{$100,00 \%$} \\
\hline \multicolumn{6}{|c|}{ Tabela 4 - Cruzamento dos parâmetros peso e tempo de coleta } \\
\hline \multirow{2}{*}{\multicolumn{2}{|c|}{ Classe }} & \multicolumn{3}{|c|}{ Variável tempo } & Total \\
\hline & & $\begin{array}{c}\text { Padrão } \\
\text { abaixo }\end{array}$ & Padrão & $\begin{array}{c}\text { Padrão } \\
\text { acima }\end{array}$ & geral \\
\hline \multirow{4}{*}{$\begin{array}{c}\text { Variável } \\
\text { peso }\end{array}$} & Padrão abaixo & 6 & 6 & 15 & 27 \\
\hline & Padrão & 2 & 8 & 21 & 31 \\
\hline & Padrão acima & 1 & 5 & 21 & 27 \\
\hline & l geral & 9 & 19 & 57 & 85 \\
\hline
\end{tabular}


pelos moradores em locais próximos ao itinerário do roteiro.

Como os itinerários dos roteiros foram mapeados por receptores GPS de dentro do caminhão coletor, e como muitas ruas são atendidas pela prestação de serviço de coleta de lixo, mas sem o acesso do caminhão coletor, constatou-se que para o cálculo da taxa de cobertura o método adotado deve receber uma complementação de um levantamento de campo que verifique em cada uma das ruas não trafegáveis o nível da prestação de serviço de coleta de lixo domiciliar. Sendo, entretanto, este tipo de trabalho complementar de uma outra natureza que não aquela proposta nesse estudo.

Contudo, o Relatório de Gestão da SEMULSP, referente ao ano de 2006, apresenta a taxa de cobertura de aproximadamente $96 \%$ para a prestação do serviço de coleta de lixo.

Algumas informações referentes aos itinerários devem ser consideradas somente para tentar entender alguns roteiros com percursos extensos, como a relação existente entre ruas percorridas e atendidas, ou seja, distância necessária percorrida pelo caminhão coletor para o atendimento das ruas de um determinado roteiro.

Adotou-se para esta análise somente as ruas atendidas pela coleta de lixo onde o caminhão coletor trafega, sem considerar as ruas e becos, as quais possuem seu lixo puxado pelos garis. É importante salientar que tal adoção pode mascarar em alguns roteiros a referida relação de ruas percorridas por atendidas, mas não o tempo total do roteiro.

Para a relação de ruas percorridas e atendidas, o ideal é que os itinerários sejam dimensionados para percorrerem aproximadamente a mesma distância a ser atendida, evitando passar por mais de uma vez em uma mesma rua, ou seja, uma razão que tenda para 1 , entretanto este não depende exclusivamente de aspectos operacionais e de planejamento sendo fortemente influenciado pelas características urbanísticas, de trânsito, topográficas e hidrográficas de cada cidade.

Os itinerários dos roteiros atuais, apresentam para a relação de ruas percorridas e atendidas uma razão média de 1,38 , ou seja, para o caminhão coletor atender $10 \mathrm{~km}$ de ruas é necessário que se desloque $13,8 \mathrm{~km}$.

Com o intuito de estabelecer classes de padrôes de eficiências dos itinerários dos roteiros quanto à Razão de Ruas Percorridas e Atendidas - RRPA e considerando a grande heterogeneidade dos valores obtidos dos 85 roteiros, distribuídos no intervalo de 1,05 a 2,39, surgiu a necessidade de identificar o padrão Manaus para esta razão.

Então, a principio, criou-se um índice de 0 a 10, sendo os valores mais próximos de 10 , aqueles que tendem para 1 e os mais próximos de 0 , aqueles que tendem para 2,39 na razão RRPA, através da fórmula:

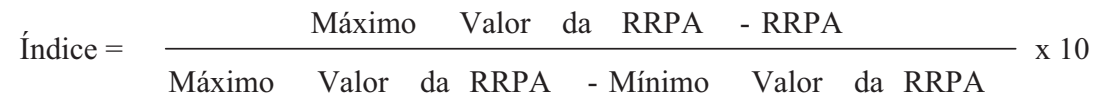

Fonte: PNUD, 2005.
A partir da obtenção dos índices para cada rota, determinou-se a moda (valor mais freqüente), onde o índice com maior representatividade foi o 8 , ou seja, os valores de 1,2534 a 1,3845 da razão conforme a Tabela 5 .

Com base nesta medida, criaramse três classes: "Não aceito", "Aceito" e "Padrão Manaus", onde, a classe "Padrão Manaus" refere-se a todos os valores da razão iguais à moda. Para a classe "Acima", adotaram-se os valores abaixo da moda e que tendem para o valor igual a 1, considerado ideal. A última classe, "Abaixo", foi composta pelos valores acima da moda (Tabela 6).

Conforme apresentado na Tabela 6, a eficiência dos itinerários dos roteiros quanto à razão de ruas percorridas e atendidas, considerando o padrão
Manaus para esta razão, apresentou um resultado satisfatório em aproximadamente $67 \%$ dos roteiros, mas ainda assim, 32,94\% dos roteiros, ou seja, aqueles que tiveram seus valores na razão acima da moda devem ter seus percursos revistos.

Outro aspecto importante analisado é que os itinerários dos caminhões coletores, na maioria dos roteiros, deixando de coletar em sua área para atender áreas vizinhas.

O não cumprimento das delimitações dos roteiros pode ocasionar dentre outros aspectos a redução na velocidade de coleta em função da ocorrência de repasses desnecessários (repetiçôes de coleta em uma mesma rua) por coletores de rotas vizinhas. Pode também não obedecem aos limites planejados,

Tabela 5 - Intervalo de classes de padrões de eficiência dos itinerários dos roteiros quanto à Razão de Ruas Percorridas e Atendidas

\begin{tabular}{cccc}
\hline Intervalo de valores da RRPA & Índice & Repetiçóes & $\%$ \\
\hline $2,3311-2,3935$ & 0 & 2 & 2,35 \\
2,0877 & 2 & 1 & 1,18 \\
1,9624 & 3 & 1 & 1,18 \\
$1,8012-1,8737$ & 4 & 4 & 4,71 \\
1,7385 & 5 & 1 & 1,18 \\
$1,5231-1,5849$ & 6 & 4 & 4,71 \\
$1,3881-1,5164$ & 7 & 15 & 17,65 \\
$1,2534-1,3845$ & 8 & 33 & 38,82 \\
$1,1283-1,2350$ & 9 & 21 & 24,71 \\
$1,0490-1,1103$ & 10 & 3 & 3,53 \\
Total & & 85 & 100 \\
\hline
\end{tabular}

Tabela 6 - Quantificação e o percentual das classes compostas pela Razão de Ruas Percorridas e Atendidas - RRPA

\begin{tabular}{ccc}
\hline Classes & Quant. & $\%$ \\
\hline Acima & 24 & $28,24 \%$ \\
Abaixo & 28 & $32,94 \%$ \\
Padrão Manaus & 33 & $38,82 \%$ \\
Total & 85 & $100,00 \%$ \\
\hline
\end{tabular}


ocasionar por indefinição de competência de coleta de uma determinada área (áreas de vizinhanças de dois ou mais roteiros) a não prestação do serviço.

Em roteiros vizinhos, geralmente, quando estes possuem limites, como avenidas de grande trafego de veículos, é comum que estejam planejados para que cada rota colete o lixo de um lado do logradouro, evitando o risco de acidentes, pois os garis não necessitam atravessar para coletar dos dois lados.

$\mathrm{O}$ ideal para um roteiro de coleta é que o mesmo obedeça aos limites da área estabelecida para o seu itinerário.

Porém, dos 85 roteiros analisados, somente 9 roteiros, ou seja, 10,6\% dos roteiros não excedem sua delimitação e 22 roteiros apresentam atendimento fora de sua delimitação em até 500 metros.

A média de extensão atendida fora da delimitação prevista para os roteiros é de 2.355 metros, ou seja, quase $10 \%$ da média de atendimento dos roteiros nos trechos de coleta. Já o intervalo com maior freqüência (moda) de distâncias atendidas fora dos roteiros é de 1.607 metros a 5.708 metros, o que reflete a necessidade imediata de revisão dos limites destes roteiros.

A partir de análises visuais do sistema viário de Manaus, constatou-se que a forma de organização do mesmo é o principal agravante para o aumento das relaçôes de ruas percorridas e atendidas e também dos trechos executados fora da delimitação prevista, uma vez que, em função das disposiçôes de tráfego nas vias (ruas de mão única, sem saída ou a inexistência de retornos).

Contudo, o geoprocessamento possui ferramentas que permitem a utilização da disposição de trânsito nas vias locais de cada roteiro, como variável no dimensionamento das áreas de abrangência e ainda de seus itinerários.

\section{Lixeiras viciadas, pontos de lixo, piso sem asfalto e declividades}

Para avaliar a interferência ou não dos parâmetros pontos de lixo (PL), lixeiras viciadas (LV), piso sem asfalto (PSA) e declividades (DL), na velocidade de coleta de lixo domiciliar dos roteiros expresso pela extensão em metros de ruas por tempo em minutos atendidos (M/MIN ATEN), optou-se por uma análise de correlação. Entretanto, com intuito de reduzir o efeito da extensão dos percursos das rotas sobre o valor quantificado de cada um dos parâmetros, os mesmos foram divididos pela extensão atendida de cada roteiro (MATEN) e posteriormente, correlacionados com a velocidade de coleta (Tabela 7).

Conforme apresentado na Tabela 7, os parâmetros lixeiras viciadas, declividades e piso sem asfalto não apresentaram correlação com a variável velocidade de coleta.

Para os parâmetros declividades e piso sem asfalto, foram quantificadas poucas ocorrências e o cálculo de moda (maior freqüência) revelou que o padrão de Manaus é formado por intervalos de 0 a 5 trechos de declividades e 0 a 1 trechos com piso sem asfalto por roteiro, respectivamente. A pouca ocorrência desses parâmetros nos trechos de coleta, pode ser atribuída à experiência dos motoristas na escolha dos itinerários e ao procedimento de coleta e transporte manual do lixo pelos garis nas áreas de difícil acesso para o caminhão coletor.

Porém mesmo não havendo a comprovação da interferência desses parâmetros com a velocidade de coleta, a identificação espacial dos mesmos, pode servir, para trabalhos posteriores, que visem à melhoria dos percursos, ou seja, utilizar estes parâmetros como obstáculos para definiçóes de roteiros (roteirização) automatizadas por meio de softwares específicos.

Quanto à não correlação das lixeiras viciadas com a velocidade de coleta, se justifica, pois, as análises de percursos, mostraram que o tempo médio gasto pelos garis, para a coleta das mesmas é de 1,5 minutos, o que não interfere no resultado final de um turno de trabalho, desde que a freqüência de lixeiras viciadas por metro de ruas atendidas não seja alta.

$\mathrm{Na}$ Figura 1 é apresentado a distribuição espacial das lixeiras viciadas nos roteiros de coleta de lixo domiciliar.
O conhecimento da localização espacial das lixeiras viciadas nos roteiros de coleta, também é um parâmetro importante, pois o mesmo serve de subsídio na escolha de áreas que devem ser orientadas pelas equipes de conscientização ambiental da SEMULSP, quanto aos problemas ocasionados pelas lixeiras viciadas. Nas áreas com grande ocorrência de lixeiras viciadas, tem-se observado que a partir da orientação das equipes de conscientização ambiental da SEMULSP, a efetiva participação da sociedade no cumprimento de horários de disposição dos resíduos, bem como, o melhor acondicionamento.

Com relação ao parâmetro "pontos de lixo", observa-se na Tabela 7, uma tendência de correlação negativa com a velocidade de coleta nos roteiros, ou seja, na medida em que os roteiros apresentem maior quantidade de pontos de lixo por metro atendido, a velocidade de coleta tende a diminuir.

\section{CONCLUSÕES E RECOMENDAÇṒES}

De acordo com o objetivo principal deste trabalho que consistiu na avaliação do atual sistema de coleta de lixo de Manaus por meios de técnicas de geoprocessamento, o mesmo foi alcançado, e o uso dessa metodologia foi eficiente tanto na coleta de informações quanto na avaliação e gerenciamento das mesmas.

Ao se analisar os roteiros de coleta de lixo domiciliar, constatou-se a complexidade dessa questão, por envolver diversos aspectos de eficiência operacional com as características próprias de cada área de abrangência, ou seja, percebeuse que cada roteiro possui seus próprios padrões de otimização em função de suas especificidades, como, características do pavimento e da disposição viária, geração per capita, densidade populacional, relação distância percorrida e atendida,

Tabela 7 - Resultado da análise de correlação dos parâmetros lixeiras viciadas, pontos de lixo, piso sem asfalto, pontos de lixo e declividades com a velocidade

\begin{tabular}{cccccc}
\hline Parâmetro & $\begin{array}{c}\text { M/MIN } \\
\text { ATEN }\end{array}$ & $\begin{array}{c}\text { PL/ } \\
\text { MATEN }\end{array}$ & $\begin{array}{c}\text { LV/ } \\
\text { MATEN }\end{array}$ & $\begin{array}{c}\text { DL/ } \\
\text { MATEN }\end{array}$ & $\begin{array}{c}\text { PSA/ } \\
\text { MATEN }\end{array}$ \\
\hline M/MIN ATEN & 1 & & & & \\
PL/MATEN & $-0,44064$ & 1 & & & \\
LV/MATEN & $-0,10859$ & $-0,1909$ & 1 & & \\
DL/MATEN & $-0,111$ & $-0,07343$ & 0,187666 & 1 & \\
PSA/MATEN & 0,219227 & $-0,0261$ & 0,006261 & 0,273147 & 1 \\
\hline
\end{tabular}




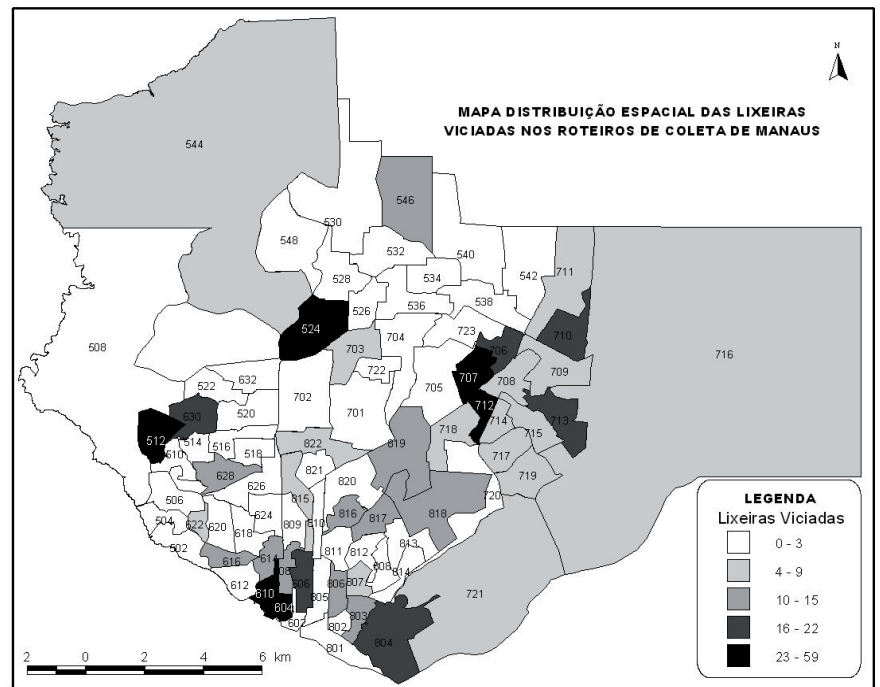

Figura I - Distribuição espacial das lixeiras viciadas nos trechos dos roteiros de coleta de lixo

relação peso produzido por extensão percorrida, deslocamentos improdutivos, entre outros.

Entretanto, o conhecimento das características física e operacional de cada área de abrangência da coleta domiciliar, e a possibilidade de analisá-las espacialmente e graficamente, tanto de modo separado quanto de modo integrado, permitem dimensionar esses roteiros, conforme suas próprias características, buscando sua otimização operacional.

Portanto, pode-se afirmar que o método proposto de avaliação de roteiros de coleta de lixo, a partir de informações georreferenciadas, tem sido uma das características mais marcantes na utilização do geoprocessamento, o qual vem se mostrando, dinâmico, eficaz e essencial dentro da rotina diária da ASTECGEO da Secretaria Municipal de Limpeza Urbana.

\section{REFERÊNCIAS}

ASSAD, E. D.; SANO, E. E. Sistemas de Informaçôes Geográficas - Aplicaçôes na Agricultura. Brasília, 1998

ASSEMAE - ASSOCIAÇÃO NACIONAL DE SERVIÇOS MUNICIPAIS DE SANEAMENTO. Curso: Dimensionamento de Frota para Coleta de Lixo. São Paulo, 1995.

BRASIL. Decreto-Lei $n^{0}$ 5452, de 1 de Maio de 1943. Dispõe sobra a Consolidação das Leis Trabalhistas, Legislação Federal, 1943.

BRETAS, A. L. Gerenciamento dos Serviços de Limpeza Pública. São Paulo, 2002.

CALIJURI M. L.; ROHM S. A. Sistemas de Informaçôes Geográficas. $1^{\circ}$ ed., Viçosa, Editora da Universidade de Viçosa, 34p.1995.
CÂMARA, G.; MEDEIROS, J. S. Geoprocessamento para Projetos Ambientais. Instituto Nacional de Pesquisas Espaciais - INPE, São José dos Campos, 1996.

CÂMARA, G. Modelos, Linguagens e Arquiteturas para Bancos de Dados Geográficos. São José dos Campos: UNICAMP, 1995. Tese (Doutorado) - Programa de Pós-Graduação em Geoprocessamento, Universidade de Campinas, São Paulo, 1995

CAMARGO, M. U. C. Os Sistemas de Informações Geográficas (SIG) como Instrumento de Gestão em Saneamento. Rio de Janeiro, 1997.

CAVALCANTE, D. Análise Ergonômica do Trabalho para os Postos de Coletores e Mooristas. Manaus, 2007.

CEPIS - CENTRO PANAMERICANO DE INGENIERIA SANITARIA Y CIENCIAS DEL AMBIENTE. Indicadores para el Gerenciamiento del Servicio de Limpieza Pública. Lima, 2002.

CHRISTOFOLETTI, A. Modelagem de Sistemas Ambientais. $1^{\circ}$ ed., São Paulo, Edgard Blücher, 236p. 1999.

CHRISTOFOLETTI, A.; TEIXEIRA, L. A. Sistemas de Informaçōes Geográficas: Dicionário Ilustrado. São Paulo, 1997.

CRUZ, O. G. Homicídios no Estado do Rio de Janeiro: análise da distribuição especial e sua evolução. São Paulo: Faculdade de Saúde Pública, USP, 1996. Dissertação de Mestrado - Programa de Pós-Graduação, Universidade de São Paulo, São Paulo, 1996.

DANTAS, A. S. Sistemas de Informação Geográfica em transporte: estudo da arte. In: CONGRESSO DE PESQUISA E ENSINO EM TRANSPORTES, Brasília, 1996. Anais.

DAVIS JUNIOR, C. A. Múltiplas Representaçōes em Sistemas de Informaçōes Geográficos. Belo Horizonte: UFMG, 2000. Tese de Doutorado - Programa de Pós-Graduação em Ciência da Computação, Universidade Federal de Minas Gerais, Minas Gerais, 2000.

FARKUH NETO, A.; LIMA, R. S. Roteirização de veículos de uma rede atacadista com o auxilio de Sistemas de Informaçōes Geográficas (SIG). In: Encontro Nacional de Eng. de Produção, Porto Alegre, 2005. Anais.

FERREIRA, B. F. Revisão de literatura e análise em planejamento de transportes usando os sistemas de informaçōes geográficas. Trabalho de Conclusão de Curso de Engenharia da Produção, Universidade Federal de Viçosa, Viçosa, 2006.

GAZOLLA, D. A.; SILVA, R. M. Caracterização Física de Resíduos Sólidos e Roteamento da Coleta de Lixo Urbano. Belo Horizonte, 2000.

HALLIDAY, H. C. Desafios Logísticos da Coleta e Transporte de Residuos: Um estudo de caso do município do Rio de Janeiro. Dissertação de Mestrado - Programa de Pós-Graduação de Administração do Instituto COPPEAD, Universidade Federal do Rio de Janeiro, Rio de Janeiro, 2003.

IBAM - INSTITUTO BRASILEIRO DE ADMINISTRAÇÃO PÚBLICA. Manual de Gerenciamento Integrado de Resíduos Sólidos. Rio de Janeiro, 2001.

IBGE - FUNDAÇÃO INSTITUTO BRASILEIRO GEOGRAFIA E ESTATÍSTICO. Censo Demográfico 2000. Rio de Janeiro, 2002.

IPT - Instituto de Pesquisas Tecnológicas do Estado de São Paulo. Lixo Municipal - Manual de Gerenciamento Integrado. São Paulo, 2000.

MELO, A. C. S.; FERREIRA FILHO, V. J. M. Sistemas de Roteirização e Programação de Veículos. Programa de Engenharia da Produção, COPPE, Universidade Federal do Rio de Janeiro, Rio de Janeiro, 2002.

PNUD - PROGRAMA DAS NACÕES UNIDAS PARA O DESENVOLVIMENTO Relatório de Desenvolvimento Humano - Brasil 2005, Brasília, 2005.

ROCHA, C. H. B. Geoprocessamento Tecnologia Transdisciplinar. Juiz de Fora, Edição do Autor, 220p. 2000

RODRIGUES, M. Geoprocessamento: um retrato atual. Revista Fator GIS. Curitiba, 1993.

SEMULSP - SECRETARIA MUNICIPAL DE LIMPEZA URBANA. Relatório de Gestão da Limpeza Pública do ano de 2004. Manaus, 2004.

Relatório de Gestão da Limpeza Pública do ano de 2006. Manaus, 2006.

STROSKI, A. A. Característica dos resíduos sólidos dispostos no aterro celular de Manaus e a aplicabilidade do composto orgânico. Manaus, 2002.

XAVIER-DA-SILVA, J.; ZAIDAN, R. T. Geoprocessamento e Análise Ambiental: Aplicaçôes. Rio de Janeiro, 2004

Endereço para correspondência:

José Olavo Nogueira Braga Secretaria Municipal de Limpeza Pública de Manaus Av. Brasil, I 335 - Compensa I 69036-I IO Manaus - AM - Brasil Tel.: (92) 9/42-75 II

E-mail:olavonbraga@yahoo.com.br 